\title{
Facial sexual dimorphism in largescaled terapon Terapon theraps Cuvier, 1829, with special reference to geometric morphometry
}

\author{
R. K. RENJITH ${ }^{1}$,A. K. JAISWAR ${ }^{2}$, S. K. CHAKRABORTY², A. T. LANDGE ${ }^{2}$, G. B. SREEKANTH ${ }^{3}$, \\ AND K. K. RAMTEKE ${ }^{2}$ \\ ${ }^{1}$ ICAR-Central Institute of Fisheries Technology, Willingdon Island, Kochi - 682 029, Kerala, India \\ ${ }^{2}$ ICAR-Central Institute of Fisheries Education, Panch Marg, Mumbai - 400 061, Maharashtra, India \\ ${ }^{3}$ ICAR-Central Coastal Agricultural Research Institute, Old Goa - 403 402, Goa, India \\ e-mail: renjith.rk@icar.gov.in
}

\begin{abstract}
Facial sexual dimorphism of Terapon theraps Cuvier, 1829 was studied through geometric morphometric method. Twenty-four landmark based morphometric distances, acquired from lateral side of head, were subjected to canonical discriminant analysis (CDA) to understand facial sexual dimorphism in the species. Scatter plot of canonical factors differentiated male and female based on measurements associated with jaws, opercle and pectoral fin. Discriminant function analysis (DFA) described sexes with $28.76 \%$ error. The study showed that geometric morphometry based sexual differentiation in fishes with no external characters is a promising tool.
\end{abstract}

Keywords: Geometric morphometry, Sexual dimorphism, Terapon theraps

Intraspecific sexual dimorphism based on shape related aspects are generally associated with reproduction (Andersson and Iwasa, 1996) but also known to rise from the response of trophic structures (e. g. mouth parts), intersexual niche partitioning (Shine, 1989), immune defense (Rolff et al., 2005), size variation (Schoener, 1969) and mobility (Bonnet et al., 2001), combined or alone. Though sexual dimorphism arises due to interaction between natural and sexual selection, female choice determines species to remain sexually dimorphic or monomorphic (Ritchie et al., 2007). These variations in morphology are hard to understand by direct observation except for some, which follow temporal appearance (Schultz, 2008) or somatic attribute (Fujimoto et al., 2010), but in most fishes, visual sexual dimorphism does not exist where fertilisation is external (Blaxter, 2001). Visualisation of interspecific variations can be facilitated by geometric morphometric techniques with statistically powerful methods by analysing shape (Rohlf, 2005). These methods statistically define and analyse coordinates of landmarks, rather than traditional measurements and are particularly useful in analysis and differentiation of closely related biological entities. This study applied landmark based geometric morphometric analysis to describe interspecific variation in largescale terapon Terapon theraps Cuvier, 1829 from Mumbai, India. Largescale terapons are identified by 4 dark bands or stripes on the lateral side of body and strong lower opercular spine (Fischer and Bianchi, 1984). They are common in marine waters and occasionally in brackishwater areas (Vari, 1984). They do not have any external sexual dimorphism. Establishment of external morphological characters can support better management plans (Merz and Merz, 2004). Therefore, results of the present study would have potential applications in stock analysis and biodiversity assessments.

A total of 61 fishes (34 female and 27 male) were collected from Versova landing centre, Mumbai, India, from June to October 2017. The specimens were transported to the laboratory in chilled condition. Since external morphology could not confirm sex, gonads were observed after dissection to segregate the males and females. Only sexually mature fishes were used for the study. The left side of each fish was photographed using a digital camera and digitised with TpsDig ver. 2.10 (Rohlf, 2006). Fourteen landmarks were selected on the head region of the fish to provide head shape summary (Fig. 1). Coordinates of landmark points were transformed to distances using PAST ver. 3.20 (Hammer et al., 2001) and a truss network was established on the head region of the fish (Fig. 2). Morphometric data of head were transformed and normality was tested using the SAS PROC UNIVARIATE procedure (SAS, 2008) to remove outliers. Since there were no outliers; the data was transformed to remove size -variation using allometric approach (Reist, 1985):

$\mathrm{M}_{\text {trans }}=\log \mathrm{M}-\left(\log \mathrm{SL}-\log \mathrm{SL}_{\text {mean }}\right)$ 
where, $M_{\text {trans }}$ is the transformed distance, $\log M$ is the natural $\log$ of original distance, $\mathrm{b}$ is the within group regression value of slope of $\log M$ on $\log \mathrm{SL}$, SL is the head length of fish and $\mathrm{SL}_{\text {mean }}$ is the sex-wise mean of head length.

Correlation coefficients between distances, prior and after transformation, were used to assess the effectiveness of transformation. In addition to correlation, MANOVA of truss distances was also performed to test significant difference between both sexes. A total of 24 truss distances were selected by discriminant function analysis (DFA) with forward selection method (STEPDISC procedure of SAS), for the study and rate of miscalculation was also

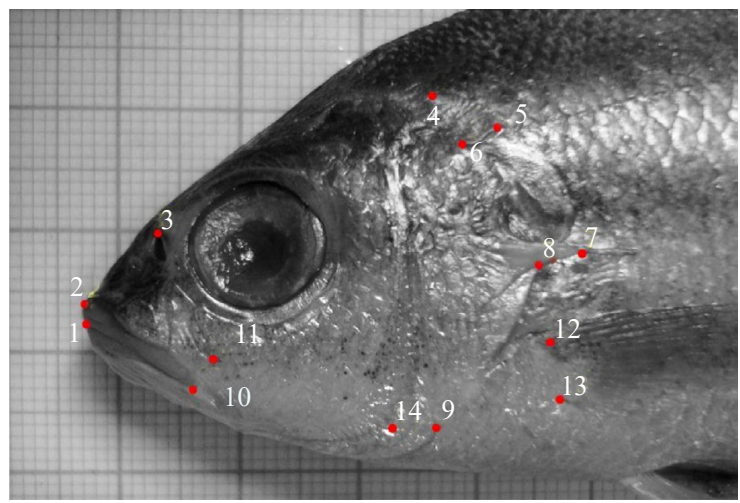

Fig. 1. Landmarks described in $T$. theraps: $(1,2)$ anterior premaxilla; (3) upper margin of nostril; (4) upper margin of post-temporal bone; $(5,6)$ lower margins of post-temporal bones; (7) lateral tip of opercular spine; (8) meeting point between opercular spine and subopercle; (9) meeting point between subopercle and postopercle; $(10,11)$ posterior margins of maxilla; $(12,13)$ pectoral fin base length; (14) tip of largest preopercular spine

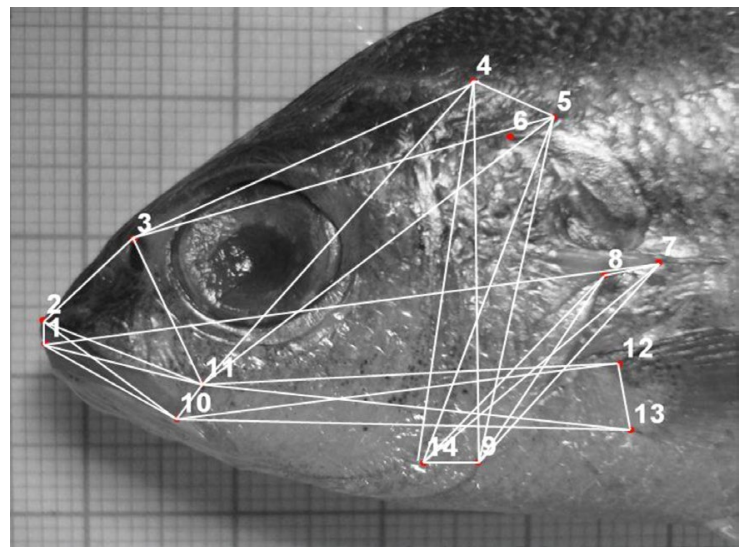

Fig. 2. Truss network of $T$. theraps with 14 landmarks in the head region estimated. This method has significantly reduced number of truss distances, so the unwanted parameters were avoided. Subsequently, canonical discriminant analysis (CDA) using PROC CANDISC procedure of SAS (SAS, 2008) was employed to distinguish between both sexes by analysing canonical discriminants in scatter plot.

Truss distances, after transformation, did not show any significant correlation with head length, which revealed that allometric transformation could successfully remove size effect from the analysis. Multivariate analysis of variance (MANOVA) could establish significant difference between both sexes (Wilk's Lambda $=0.2611$, $\mathrm{F}=4.24, \mathrm{p}<0.0001)$ for truss distances, selected from DFA. CDA of truss distances for sexes (Table 1) indicated that variable 4-11 and 5-14 had the highest loading values (0.4) in the first canonical factor (Can1). These factors were associated with opercular morphometry followed by lowest values of loading (0.3) of variables 4-9, 5-9, 7-14 and 11-12 of opercular region. Variables 10-11 and 12-13 also indicated same value of first factor associated with variations of mouth and pectoral fin base length. Lowest values of canonical (0.2) factor were found to be associated to mouth part variables 1-11, 2-11 and 3-11.

The total variations in morphometry pertained to operculum, jaws and pectoral fin. Factor loadings (Can1, Can2 and Can3) were correlation between variables and factors. The results revealed that major variation in sex is due to opercular measurements followed by measurements of jaws, while least variation was in pectoral fin measurements. The jaw related measurements were found to be negatively correlated in determining sex, while other variables were positive (Figs. 3a,b,c). To understand variation in distribution of both sexes, a bivariate plot, using Can1 and Can2, was plotted (Fig. 4). The DFA of 24 truss distances had misclassification rate of $28.76 \%$, where female fishes had a misclassification rate of $11.11 \%$ and male had $17.65 \%$ (Table 2).

Sexual dimorphism in many fishes is caused due to the reproductive role of the sexes which may influence selection pattern and subsequently results in morphological variation. Competition in males may result in adaptations like variation in operculum seen in fishes of the family Labridae. Larger fins of males help them position themselves during spawning to maximise fertilisation rate (Casselman and Schulte-Hostedde, 2004). Some studies on sharks have shown that pre-oral length of males are significantly shorter than females due to increased mouth size (Ellis and Shackley, 1995). In the present study, variation in morphometry in $T$. theraps was evident in operculum, snout and jaws and pectoral fin. Female fish may have bigger head length to increase buccal volume to feed on macrobenthos (Caldecutt and 
Table 1. Variable loadings represented as total canonical structure from forward selection

\begin{tabular}{|c|c|c|c|}
\hline Variable & Can1 & Can2 & Can3 \\
\hline $1-2$ & -0.09875 & 0.008313 & 0.016334 \\
\hline $1-10$ & -0.1101 & 0.009784 & 0.038998 \\
\hline $1-11$ & -0.20903 & 0.017408 & 0.036014 \\
\hline $2-10$ & -0.12036 & 0.011683 & 0.026215 \\
\hline $2-11$ & -0.2472 & 0.019842 & 0.047588 \\
\hline $3-4$ & 0.191382 & -0.01316 & -0.02158 \\
\hline $3-5$ & 0.123427 & -0.0124 & -0.02746 \\
\hline $3-11$ & -0.22904 & 0.02165 & 0.051843 \\
\hline $4-5$ & 0.16609 & -0.01537 & -0.02558 \\
\hline $4-9$ & 0.372863 & -0.03631 & -0.12202 \\
\hline 4-11 & 0.121659 & -0.01096 & -0.01708 \\
\hline 4-14 & 0.406757 & -0.03223 & -0.04655 \\
\hline $5-9$ & 0.331714 & -0.02722 & -0.06902 \\
\hline $5-14$ & 0.428634 & -0.03729 & -0.02478 \\
\hline $7-8$ & 0.223058 & -0.02111 & -0.01363 \\
\hline $7-9$ & 0.159805 & -0.01435 & -0.01104 \\
\hline $7-14$ & 0.327163 & -0.02812 & -0.053 \\
\hline $8-14$ & 0.224212 & -0.02 & -0.02375 \\
\hline $10-11$ & 0.39041 & -0.03351 & -0.04448 \\
\hline $10-12$ & 0.291091 & -0.02868 & -0.05864 \\
\hline $10-13$ & 0.201332 & -0.01879 & -0.04097 \\
\hline $11-12$ & 0.325728 & -0.02681 & -0.04912 \\
\hline $11-13$ & 0.229594 & -0.02192 & -0.03543 \\
\hline $12-13$ & -0.30101 & 0.024522 & 0.068078 \\
\hline
\end{tabular}

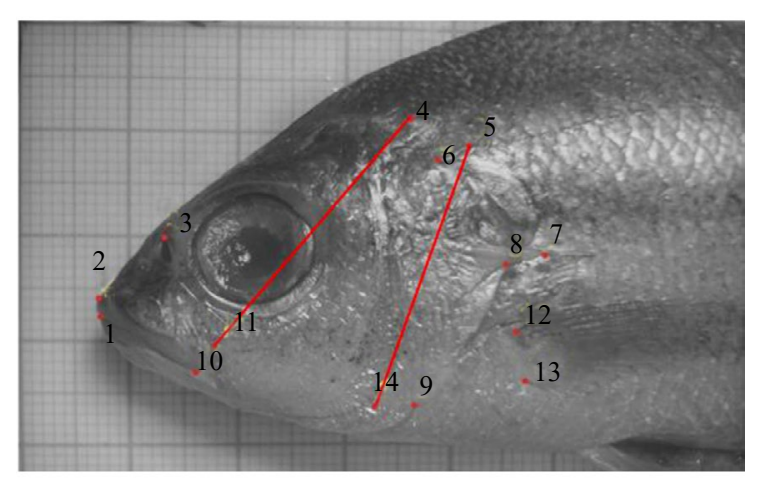

(a)
Adams, 1998). Jaw shape variation in same species is attributed to differential feeding behaviour or temporal shift in feeding niche. Female fishes are known to avoid feeding during spawning season or may keep a steady diet and also provide buccal incubation (Schmitt et al., 2015).

Sexual dimorphism in T. theraps is unclear due to the absence of secondary sexual characters such as enlarged

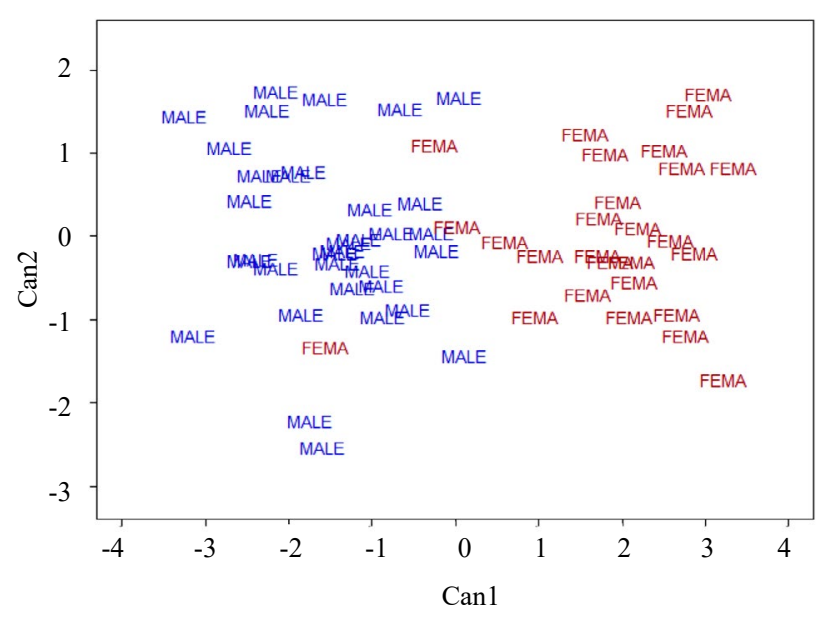

Fig. 4. Scatter plot of first two canonical score showing separation in sex (Female-FEMA, Male-MALE)

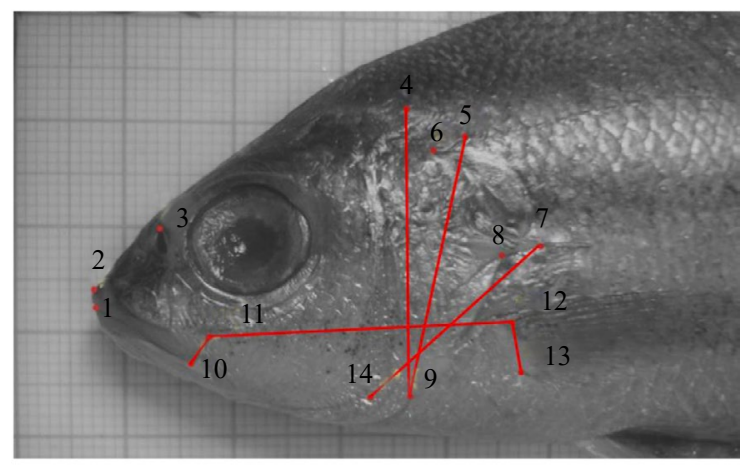

(b)

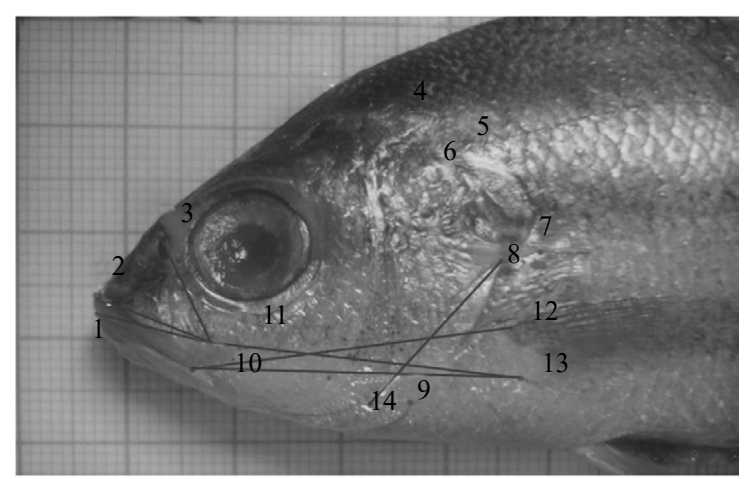

(b)

Fig. 3. Canonical score for (a) Opercular measurement (score - 0.4); (b) Opercle, pectoral fin and jaw measurements (Score - 0.3); (c) Canonical score loadings for opercular measurement (Score - 0.2) 
Table 2. Percentage of fish from each sex classified in cross validation of discriminant function analysis

\begin{tabular}{lllll}
\hline Sex & & Female & Male & Total \\
\hline Female & Number & 24 & 3 & 27 \\
& Percentage & 88.89 & 11.11 & 100 \\
\hline Male & Number & 6 & 28 & 34 \\
& Percentage & 17.65 & 82.35 & 100 \\
\hline Total & Number & 30 & 31 & 61 \\
& Percentage & 49.18 & 50.82 & 100 \\
\hline
\end{tabular}

belly which may arise during spawning season in most fishes. For fishes like T. theraps, where sexual dimorphism is unclear, geometric morphometry could serve as a great tool to complement ecological studies. Measurements pertaining to ecomorphologically associated regions were found significant in separating sexes, showing that sex is an ecomorphologically dependent factor in T. theraps. The rate of misclassification found by DFA is $28.76 \%$ in T. theraps, where the success of classification depends on additive effect of all characters.

Management of any fish species requires knowledge in sexual dimorphism to implement specific management plans for both sexes which may differ. Although molecular tools are available for the same purpose, a low-cost methodology of geometric morphometry can be employed to avoid time taking procedures. This can be achieved through developing algorithm-based image readers on which field identification of the species can be developed. Once a database is developed, rapid identification can be achieved and unnecessary sacrificing of fish can also be avoided. The same study may be extended to other species of fishes without external sexual characters to understand sexual dimorphism.

\section{Acknowledgements}

The authors thank the Director, ICAR-CIFE, Mumbai and Indian Council of Agriculture Research, New Delhi for providing all necessary facilities to conduct this study.

\section{References}

Andersson, M. and Iwasa, Y. 1996. Sexual selection. Trends Ecol. Evol., 11(2): 53-58. https://doi.org/10.1016/01695347(96)81042-1.

Blaxter, J. H. S. 2001. Fish reproduction. In: Steele John H. (Ed.), Encyclopedia of ocean sciences, $2^{\text {nd }}$ edn. Academic Press, Cambridge, Massachusetts, USA, p. 425-431.

Bonnet, X., Lagarde, F., Henen, B. T., Corbin, J., Nagy, K. A., Naulleau, G., Balhoul, K., Chastel, O., Legrand, A. and Cambag, R. 2001. Sexual dimorphism in steppe tortoises (Testudo horsfieldii): Influence of the environment and sexual selection on body shape and mobility. Biol. J. Linn. Soc., 72(3): 357-372. https://doi.org/10.1006/bijl. 2000.0504
Caldecutt, W. J. and Adams, D. C. 1998. Morphometrics of trophic osteology in the threespine stickleback, Gasterosteus aculeatus. Copeia, 4: 827-838.

Casselman, S. J. and Schulte-Hostedde, A. I. 2004. Reproductive roles predict sexual dimorphism in internal and external morphology of lake whitefish, Coregonus clupeaformis. Ecol. Freshw. Fish., 13: 217-222. https://doi.org/10.1111/ j.1600-0633.2004.00053.x.

Ellis, J. R. and Shackley, S. E. 1995. Ontogenetic changes and sexual dimorphism in the head, mouth and teeth of the lesser spotted dogfish. J. Fish Biol., 47: 155-164. https:// doi.org/10.1111/j.1095-8649.1995.tb01881.x.

Fischer, W. and Bianchi, G. 1984. FAO species identification sheets for fishery purposes. Western Indian Ocean (Fishing Area 51). Prepared and printed with the support of the Danish International Development Agency (DANIDA). Food and Agriculture Organisation of the United Nations, Rome, Italy.

Fujimoto, T., Nishimura, T., Goto-Kazeto, R., Kawakami, Y., Yamaha, E. and Arai, K. 2010. Sexual dimorphism of gonadal structure and gene expression in germ cell-deficient loach, a teleost fish. Proc. Natl. Acad. Sci., 107(40): 17211-17216. https://doi.org/10.1073/pnas.1007032107.

Hammer, O., Harper, D. A. T. and Ryan, P. D. 2001. PAST: Paleontological Statistics Software Package for Education and Data Analysis. Palaeontologia Electronica, 4(1): 1-9.

Merz, J. and Merz, W. 2004. Morphological features used to identify chinook salmon sex during fish passage. Southwestern Naturalist, 49(2): 197-202.

Reist, J. D. 1985. An empirical evaluation of several univariate methods that adjust for size variation in morphometric variation. Can. J. Zool., 63: 1429-1439.

Ritchie, M. G., Hamill, R. M., Graves, J. A., Magurran, A. E., Webb, S. A. and Macías Garcia, C. 2007. Sex and differentiation: Population genetic divergence and sexual dimorphism in Mexican goodeid fish. J. Evol. Biol., 20: 2048-2055. doi: 10.1111/j.1420-9101.2007.01357.x.

Rohlf, F. J. 2005. Geometric morphometrics simplified, Trends Ecol. Evol., 20(1): 13-14,

Rohlf, F. J. 2006. TpsDig Version 2.1.0. Department of Ecology and Evolution, State University of New York at Stony Brook, New York, USA.

Rolff, J., Armitage, S. A. O. and Coltman, D. W. 2005. Genetic constraints and sexual dimorphism in immune defense. 
Evolution, 59: 1844-1850. https://doi.org/10. 1111/j.00143820.2005.tb01831.x.

SAS 2008. SAS/STAT User's guide, version 9.1, vol. 1., $4^{\text {th }}$ edn. SAS Institute, Cary, North Carolina, USA, 943 pp.

Schmitt, J. D., Gedamke, T., DuPaul, W. D. and Musick, J. A. 2015. Ontogenetic and sex-specific shifts in the feeding habits of the barndoor skate. Mar. Coast. Fish., 7(1): 409-418.

Schoener, T. 1969. Models of optimal size for solitary predators. Am. Nat., 103(931): 277-313.
Schultz, E. T. 2008. A sex difference in seasonal timing of birth in a livebearing fish. Copeia, (3): 673-679.

Shine, R. 1989. Ecological causes for the evolution of sexual dimorphism: A review of the evidence. Q. Rev. Biol., 64(4): 419-461.

Vari, R. P. 1984. Teraponidae. Terapon-perches, terapons. In: Fischer, W. and Bianchi, G. (Eds.), FAO species identification sheets for fishery purposes. Western Indian Ocean Fishing area 51, Food and Agriculture Organisation of the United Nations, Rome, Italy. 